\title{
Multiple Cropping Intensity in China Derived from Agro-meteorolo- gical Observations and MODIS Data
}

\author{
YAN Huimin $^{1}$, XIAO Xiangming ${ }^{2}$, HUANG Heqing ${ }^{1}$, LIU Jiyuan ${ }^{1}$, CHEN Jingqing ${ }^{1}$, BAI Xuehong ${ }^{1}$ \\ (1. Institute of Geographic Sciences and Natural Resources Research, Chinese Academy of Sciences, Beijing 100101, China; 2. De- \\ partment of Botany and Microbiology, Center for Spatial Analysis, University of Oklahoma, Norman, Oklahoma 73019-5300, USA)
}

\begin{abstract}
Double- and triple-cropping in a year have played a very important role in meeting the rising need for food in China. However, the intensified agricultural practices have significantly altered biogeochemical cycles and soil quality. Understanding and mapping cropping intensity in China's agricultural systems are therefore necessary to better estimate carbon, nitrogen and water fluxes within agro-ecosystems on the national scale. In this study, we investigated the spatial pattern of crop calendar and multiple cropping rotations in China using phenological records from 394 agro-meteorological stations (AMSs) across China. The results from the analysis of in situ field observations were used to develop a new algorithm that identifies the spatial distribution of multiple cropping in China from moderate resolution imaging spectroradiometer (MODIS) time series data with a $500 \mathrm{~m}$ spatial resolution and an 8-day temporal resolution. According to the MODIS-derived multiple cropping distribution in 2002, the proportion of cropland cultivated with multiple crops reached $34 \%$ in China. Double-cropping accounted for approximately $94.6 \%$ and triple-cropping for $5.4 \%$. The results demonstrat that MODIS EVI (Enhanced Vegetation Index) time series data have the capability and potential to delineate the dynamics of double- and triple-cropping practices. The resultant multiple cropping map could be used to evaluate the impacts of agricultural intensification on biogeochemical cycles.
\end{abstract}

Keywords: agricultural intensification; multiple-cropping; crop calendar; agro-meteorological observation; moderate resolution imaging spectroradiometer (MODIS)

Citation: Yan Huimin, Xiao Xiangming, Huang Heqing, Liu Jiyuan, Chen Jingqing, Bai Xuehong. Multiple cropping intensity in China derived from agro-meteorological observations and MODIS data. Chinese Geographical Science. doi: 10.1007/s11769-013-0637-2

\section{Introduction}

Multiple cropping, a rotation of two or more crops per year in a unit cropland area, is an important component of Chinese farming practices, particularly in the southern China where intensive cropping (double- and/or triple-cropping) has been widely deployed (Frolking et al., 2002; Qiu et al., 2003). Over the past several decades, multiple cropping has played a very important role in ensuring food security of China (Qiu et al., 2003). Nevertheless, agricultural intensification has increased the pressure on water resources, ecosystems and biodiversity because of increased water withdrawals for irrigation, higher energy inputs for mechanization and increased use of chemical fertilizers (Dogliotti et al., 2004; Ren et al., 2011). Agricultural land use practices alter biogeochemical cycles and soil productivity and consequently cause considerable adverse effects on the eco-

Received date: 2012-09-12; accepted date: 2012-12-17

Foundation item: Under the auspices of Strategic Priority Research Program-Climate Change: Carbon Budget and Relevant Issues of Chinese Academy of Sciences (No. XDA05050602), Major State Basic Research Development Program of China (No. 2010CB950904), National Natural Science Foundation of China (No. 40921140410, 41071344), Land Cover and Land Use Change Program of National Aeronautics and Space Administration, USA (No. NAG5-11160, NNG05GH80G)

Corresponding author: YAN Huimin. E-mail: yanhm@igsnrr.ac.cn

C Science Press, Northeast Institute of Geography and Agroecology, CAS and Springer-Verlag Berlin Heidelberg 2013 
logical environment and food production, as has been observed in many parts of the world (Vitousek et al., 1997; Yang and Li, 2000; Stoate et al., 2001; Wu et al., 2003; Foley et al., 2005; Stockholm, 2005; Eickhout et al., 2006; Tilman et al., 2011). Therefore, knowing the extent and intensity of multiple cropping is very important to ensure food security and to understand the carbon exchange processes in agro-ecosystems (Frolking et al., 1999; Hurtt et al., 2001).

Because of the lack of spatially explicit multiple cropping information, the effects of temporal change on cropland management practices have often been ignored in the simulation of the biogeochemical cycle processes, especially for the water, carbon and nitrogen cycles ( $\mathrm{Li}$ et al., 2003; Ren et al., 2011). Cropping intensity data remain a major source of uncertainty in the calculation of the carbon balance and potential soil carbon sequestration within agro-ecosystems (Defries et al., 1999; Cao et al., 2002; Yan et al., 2007). The underestimation of Gross Primary Productivity (GPP) by the moderate resolution imaging spectroradiometer (MODIS) GPP product (MOD17) further highlighted the necessity of accounting for multiple cropping in satellite-based light use efficiency models for GPP estimation. The GPP from the MOD17 data product within $\mathrm{C} 3$ and $\mathrm{C} 4$ crop rotation cropland only accounted for about $1 / 5-1 / 3$ of the carbon flux tower-estimated GPP (Zhang et al., 2008; Yan et al., 2009).

Multiple cropping patterns are controlled by physical, edaphic and climatic elements along with agronomic practices and farmers' behaviors. Traditionally, there were two approaches to obtain the estimations of cropland area and cropping intensity in a country: agricultural census statistics and land survey (Frolking et al., 2002; Qiu et al., 2003). The agricultural census data of China contain information on the distribution of crop types and total cropland area but have no detailed, spatially explicit information on the distribution of doubleand triple-cropping fields. Moreover, the collection of county-level agricultural statistics is often a time-consuming and resources-intensive process carried out by governmental agencies, and these statistics are not readily available to the public in the same calendar year. Satellite remote sensing technology provides an important, viable and practical approach for mapping, measuring and monitoring land surface dynamics on regional and global scales. Time series observations from the
National Oceanic and Atmosphere Administration's Advanced Very High Resolution Radiometer (NOAA/ AVHRR), the Systeme Probatoire d'Observation de la Terres' Vegetation sensor (SPOT/VGT) and the MODIS have provided useful datasets for identifying and monitoring land use change, vegetation dynamics and key phenological transition dates (Defries et al., 2000; Friedl et al., 2002; Xiao et al., 2002a; Xiao et al., 2002b; Liu et al., 2003b). Vegetation indices from MODIS imagery such as the normalized difference vegetation index (NDVI), the enhanced vegetation index (EVI) and the land surface water index (LSWI), have been proven effective in quantifying vegetation greenness, canopy water content and cropping intensity (Xiao et al., 2005a; 2005b; Xiao et al., 2006). The results of several previous studies showed that MODIS data at a moderate spatial resolution $(500 \mathrm{~m})$ and with a high temporal frequency (daily and 8-day) could be used to identify crop growth curves and multiple cropping areas on a large scale (Zhang et al., 2003; Sakamoto et al., 2005; Sakamoto et al., 2006; Zhang et al., 2006; Biradar and Xiao, 2011). Temporal profile analysis approach, identifying cropping intensity (single-, double- and triple-cropping per year) based on MODIS vegetation indices (e.g., NDVI, EVI and LSWI) time series data at individual pixels over large spatial domains, is a relatively new and evolving approach. This approach takes the advantage of MODIS-derived time series data (at eight-day intervals) of vegetation indices that vary seasonally and are correlated with biophysical and biochemical properties of vegetation and the land surface (Xiao et al., 2002b). This method had been used in cropping system or cropping intensity detection from noise removed (Sakamoto et al., 2006), or original MODIS time series data (Biradar and Xiao, 2011). One of the advantages of the time-oriented approach is that the classification of a land cover type can be automated and is independent from users. However, it is important to note that this approach still requires an intensive, detailed study of signal detection methods at typical cropping system regions in order to identify cropping intensity features at regional to global scales.

One way to identify land cover types from satellite images is acquiring prior knowledge by compare remote sensing data against field observations. The Chinese Meteorological Agency established and operated more than 400 agricultural meteorological stations (AMSs), 
covering most arable land and major crop types in China. The records of crop growth at these AMSs provide detailed information on crop types and crop calendar, which are helpful for understanding cropping intensity and for assessing satellite products. This study aimed to develop a rule-based algorithm for identifying multiple cropping fields from MODIS time series curve, and the capability of MODIS time series images to catch the crop growth cycle within multiple cropping areas was evaluated against field observed data. The developed MODIS-based method could produce a national-scale multiple cropping intensity dataset of China at $500 \mathrm{~m}$ spatial resolution, which could then be used for biogeochemical modeling and food security assessment.

\section{Data Sources}

\subsection{Crop calendar data from agro-meteorological stations}

To understand the temporal dynamics and spatial distribution of cropping systems from in situ ground observations, we collected crop phenological data observed in 2002 at 394 AMSs across China (Fig. 1). At each AMS, key crop growth phases, including planting date, emer- gence date and maturity date, of 11 major crop types (early rice, late rice, single rice, winter wheat, spring wheat, spring maize, summer maize, cotton, soybean, sorghum and rapeseed) were routinely observed and recorded throughout one year. The stations in the southern China featured up to 5 crop types, and the stations in the northern China typically featured 1-2 crop types (Fig. 1).

\subsection{Time series data from MODIS}

MODIS is an optical sensor onboard the Terra and Aqua satellites. The MODIS scans Earth's entire surface every 1-2 days, acquiring data in 36 spectral bands. Out of the 36 spectral bands, 7 bands can be used to study vegetation and land surfaces: blue $(459-479 \mathrm{~nm})$, green $(545-565 \mathrm{~nm})$, red $(620-670 \mathrm{~nm})$, near infrared (NIR1: 841-875 nm; NIR2: $1230-1250 \mathrm{~nm}$ ), and shortwave infrared (SWIR1: 1628-1652 nm; SWIR2: 2105-2155 $\mathrm{nm})$. The MODIS Land Science Team provides a suite of standard MODIS data products to users, including the 8-day composite MODIS Surface Reflectance Product (MOD09A1) with $500 \mathrm{~m}$ spatial resolution. We downloaded MOD09A1 datasets for 2002 from USGS (United States Geological Survey) EROS (Earth Re-

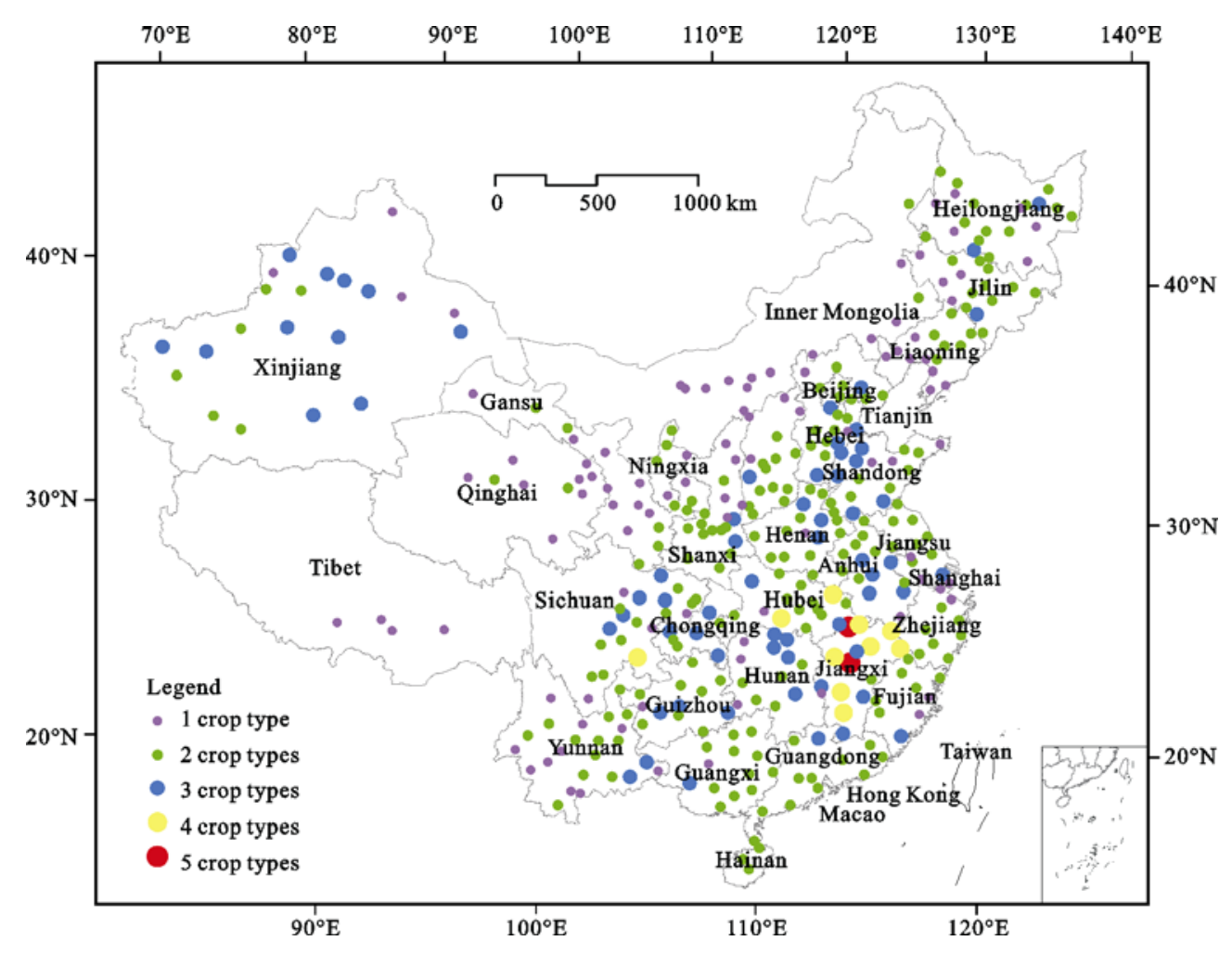

Fig. 1 Number of tracked crop types in agro-meteorological stations across China 
sources Observation and Science) Data Center; there are 468 -day composites in a year. The EVI is sensitive to light absorption by leaf chlorophyll, and has a higher sensitivity than that of NDVI in high biomass areas (Huete et al., 2002). Therefore, we used EVI in this study. We calculated EVI from the surface reflectance data of the MOD09A1.

$$
E V I=2.5 \times \frac{\rho_{\text {nir }}-\rho_{\text {red }}}{\rho_{\text {nir }}+6 \times \rho_{\text {red }}-7.5 \times \rho_{\text {blue }}+1}
$$

where $\rho_{\text {nir }}, \rho_{\text {red }}$ and $\rho_{\text {blue }}$ are the values of reflectance of NIR1, red and blue bands, respectively (Huete et al., 2002).

\subsection{Cropland dataset from Landsat ETM images}

China's National Land-Use/Land-Cover Dataset 2000 (NLCD2000) at a 1:100000 scale was generated from the analysis and manual digitalization of Landsat ETM+ images acquired in 1999 and 2000 (Liu et al., 2002). Liu et al. $(2002 ; 2003 \mathrm{a} ; 2005)$ provided details on how Landsat ETM+ images were used to produce the NLCD 2000. In this study, we used the NLCD2000 dataset to examine the consistency of multiple cropping areas presented in the MODIS dataset and in the NLCD2000 before using the MODIS dataset to evaluate agricultural intensification patterns across China. Because the NLCD 2000 cropland area data are in a vector format and the corresponding estimated MODIS agricultural intensification data are in a raster format, we used a method developed by Liu et al. (2002) to fuse and then aggregated the NLCD2000 land use data to pixels that had the same resolution as the MODIS data. This method enables conversion of the NLCD2000 vector data into a series of grid data without the loss of acreage information in such a form that the area of each type in the $500 \mathrm{~m}$ grid is consistent with its counterpart in the original, highresolution vector data.

\section{Methods}

The EVI time series data generated from the MODIS surface reflectance data include various noise components such as aerosols and bidirectional reflectance distribution factors; thus, it is necessary to reprocess these data to remove the noise components before using them for the discrimination of crop growth curves. To screen and remove cloud-contaminated observations and to apply temporal interpolation to reconstruct gapless images, the method of Harmonic Analysis of Time Series (HANTS) was used in this study (Verhoef et al., 1996). In the HANTS method, only the amplitudes and phases for (low) frequencies specified by users are computed, and a reconstruction of images based on HANTS outputs returns a smoothed time series, in which high-frequency information (e.g., sudden changes due to incidental cloud cover) will be removed. The advantage of using the HANTS method to identify crop growth curves is that it considers only the most significant frequencies expected to be present in the time series and applies a least-square curve fitting procedure based on harmonic components (Roerink et al., 2000).

According to EVI time series curves, maximum EVI appears around the heading date (Yan et al., 2008; Yan et al., 2010). Leaf area and EVI gradually increase as vegetative growth stages progresses over time and reach the peak value on the heading date, and then begin to decline in reproductive growth stage until crop mature and is harvested. We defined the date of maximum EVI in the temporal profile as the estimated heading date. Therefore, in this study we assumed that the smoothed time profile of EVI shows a peak on the heading date. Identifying the cropping intensity from the annual crop growth profile requires determining the number of growth cycles of a crop on the curve because the EVI profiles are usually irregular in mixed pixels. However, the time series data of EVI sometimes exhibit two or three troughs within one crop growth season. Directly using the number of peaks on a smoothed EVI time series profile by HANTS as the number of cropping cycles may lead to inaccurate results.

Several steps are deployed to determine reasonable peak values in the EVI profiles so as to derived multiple cropping intensity map:

The first step is to set a threshold for possible minimum peak value (the threshold value in this study was set to 0.35 which is equivalent to the peak value in semiarid grasslands), to search for points along a smoothed EVI profile, and to finally select the local maximal points (peaks) that satisfy the condition of EVI values higher than 0.35 .

The second step is to calculate the temporal interval between two probable peak dates of crop growth. According to the field-observed crop calendar information, 
both crop emergence and maturity dates are centered on three intervals in most stations (Fig. 2). The starting dates (sowing and/or reviving) of the triple-cropping seasons occur from early March to the end of May, from early June to the end of July and from early October to mid-December (Fig. 2a). The ending dates (harvesting) occur from the end of March to late June, from the end of June to mid-August and from late August to late November (Fig. 2b). The starting date of the third interval (from early October to mid-December) and the ending date of the first interval (from early March to the end of May) correspond to the reviving and maturity time of winter wheat, respectively (Figs. 2c, 2d). Therefore, in the multiple cropping intensity algorithms, it is presumed that if the interval is less than 80 days, it is possible that the two probable peaks are misclassified due to the anomalous EVI data around the true peaks. According to nation-wide crop phenologic records, the crop growth days in China should be higher than 80 .

The third step excludes those detected peaks that occur earlier than day of year $(\mathrm{DOY})=56$ or later than DOY $=320$ because probable starting dates in January, February and December are unrealistic in terms of na- tional crop phenologic records. Finally, the number of growth seasons for each crop per year is determined by averaging the numbers of the estimated heading dates in all of the years concerned.

\section{Results}

\subsection{Cropping intensity and cropping calendar ob- served from in situ agro-meteorological stations}

The records of the crop calendar observed at 394 AMSs show that crop emergence or maturity dates stretch throughout more than 10 months of a year (Fig. 2), and the temporal distribution of crop emergence or maturity date varies from the north to south in China (Fig. 3). Triple-cropping only occurred in 10 stations, 8 stations of which are located in Jiangxi Province. Double-cropping systems occurred in 186 stations which were distributed extensively within multiple cropping regions in China (Fig. 4). Among the 8 major crops recorded at AMSs, winter wheat, early rice, late rice, summer maize and rapeseed are the major food crops cultivated in the multiple cropping regions, and our analysis will therefore be focused on these crop cycles.
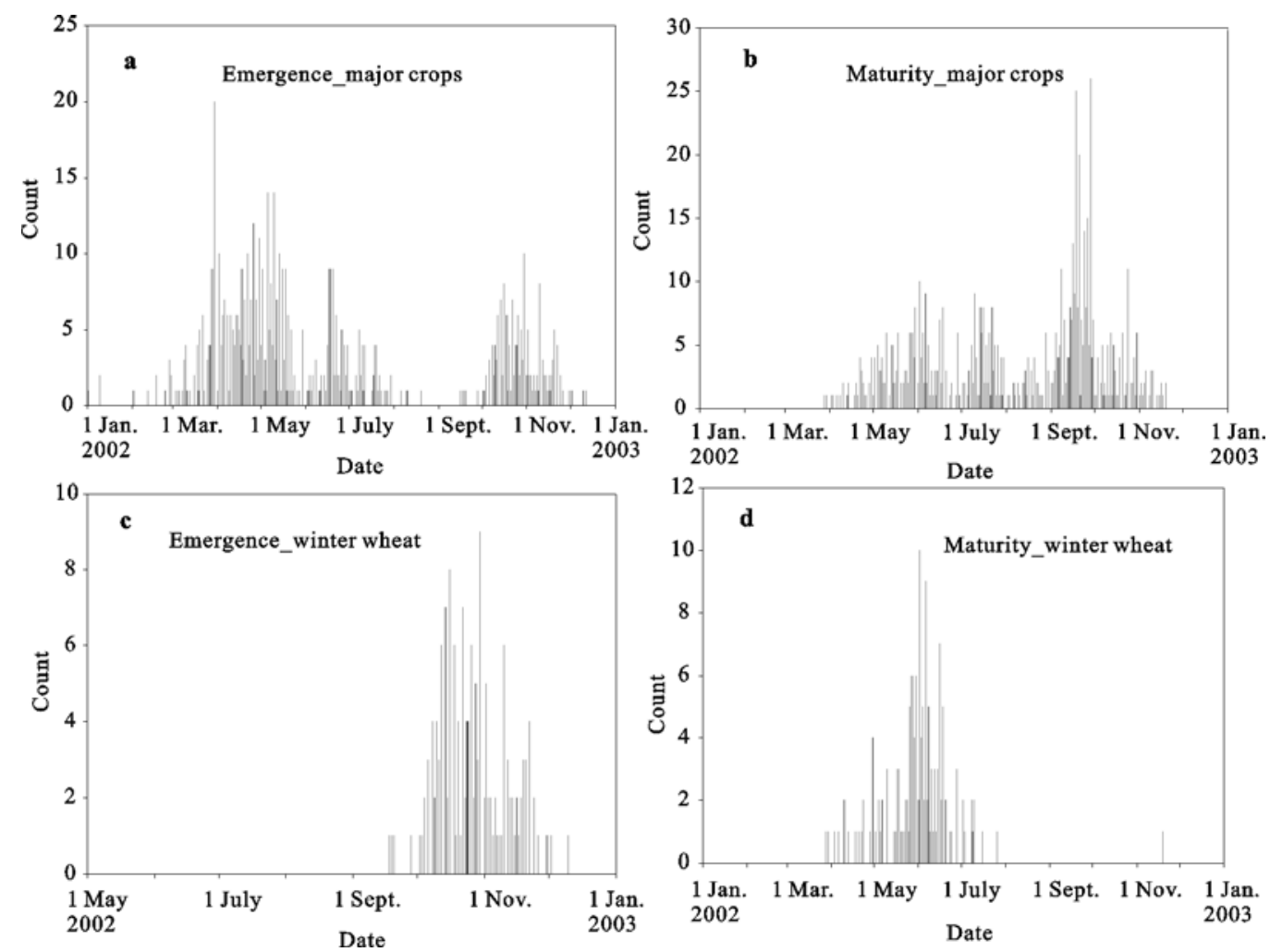

Fig. 2 Frequency of time on emergence (a) and maturity (b) of major crops, and frequency of time on emergence (c) and maturity (d) of winter wheat in China (the original data come from China's agro-meteorological observation.) 


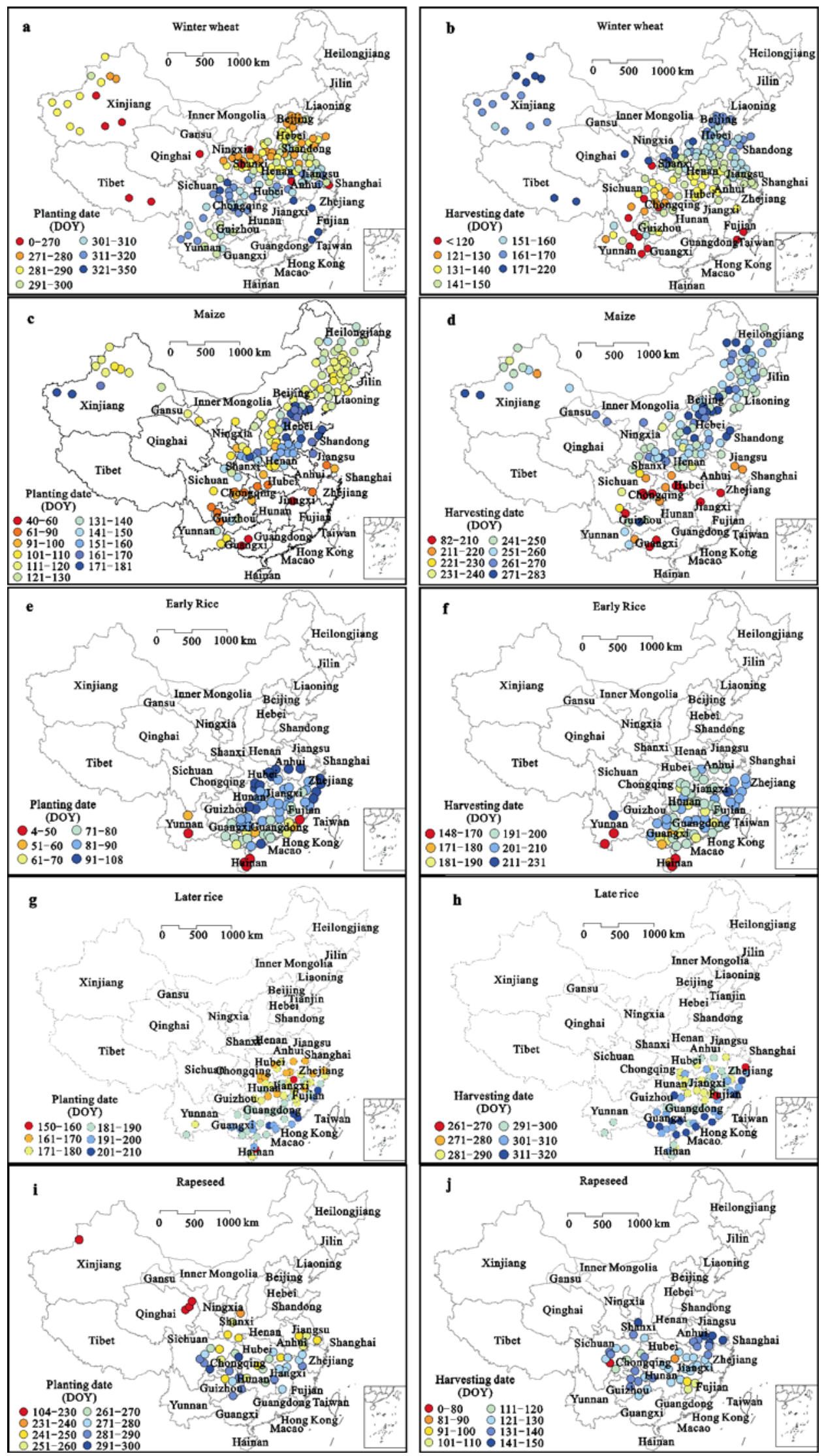

Fig. 3 Planting and harvesting date of winter wheat, maize, rice and rapeseed throughout China from agro-meteorological stations 


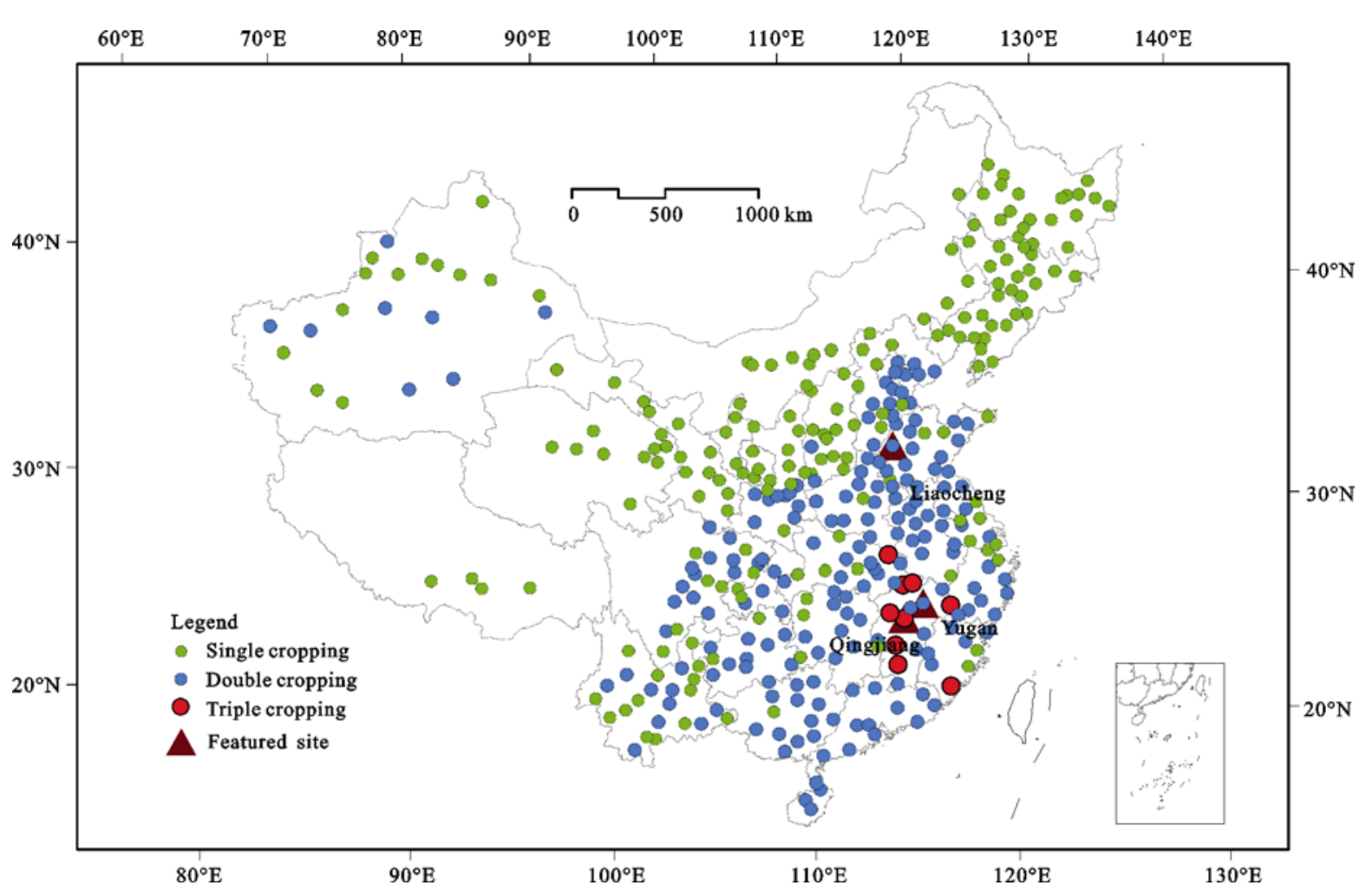

Fig. 4 Multiple cropping distribution in 2002 from agro-meteorological stations across China

Figure 3 presents the difference of the planting and harvesting time for the above-mentioned crop types with different colors. The planting date of winter wheat (Fig. 3a) from north to south gradually postponed from the earliest date in mid-September in the northern plains to the latest date in the second half of December towards the south, and the time span between earliest and latest winter wheat recovery date reach up to 60 days. The harvesting date has a trend that is the reverse of the planting date (Fig. 3b). The spatial transition pattern of crop cultivation from the north to south shows that the temperature conditions control the time of planting and harvesting for winter wheat. Maize (Figs. 3c, 3d), rice (Figs. 3e, 3f, 3g, 3h) and rapseed (Figs. 3i, 3h) do not exhibit such an obvious spatial transition pattern as winter wheat. The time differences reach up to 53 days within the emergence date of summer maize and 59 days within the maturity date of summer maize. Among the cultivation sites of late rice, the planting time in the north is generally $40-50$ days ahead of the south, and there are 30-40 days time difference in the harvesting dates. For early rice almost no obvious zonal transition is observed from the records of cultivation and harvest dates.

\subsection{Capability of crop growth cycle description of MODIS EVI time series data}

The field observational data from AMSs describe an average or normal crop information around each station rather than the site-specific. The MODIS pixels with a spatial resolution of $500 \mathrm{~m}$ usually include a mosaic of different vegetation types or crops that cause significant spatial variability in phenology. To examine the ability of 8-day composited MODIS time series data to track multiple cropping features, the ideal representative stations should consist of large crop fields with uniform crop types. From a 1 : 100000 cropland map (Liu et al., 2005), three stations are selected to examine whether the MODIS time series data are capable of tracking multiple cropping seasons and their key phenological stages (Fig. 4). The Yugan and Qingjiang stations were located in the Poyang Lake area, one of the most intensified agricultural regions in the southern China. Around the two selected stations, multiple-cropping systems exhibit a rotation of rapeseed-late rice and rapeseed-early rice-late rice over a year (Yan et al., 2008). The Liaocheng station is another selected station where a rotation of winter wheat-summer maize occurred, and this crop rotation 
dominated over the largest double-cropping plains, the Huanghe-Huaihe-Haihe plain, in the northern China (Yan et al., 2009; Yan et al., 2010). The observed phenological dates from the three selected stations are compared with seasonal dynamics of crop growth derived from the MODIS time series data to determine whether 8-day intervals in MODIS-based crop growth curves are able to describe the growth cycles of multiple crops accurately (Fig. 5).

The seasonal dynamics of the EVI derived from MODIS images in the Poyang Lake area are characterized by two cycles in the Yugan station and three cycles in the Qingjiang station. The field site at the Yugan station has a rotation of rapeseed and late rice (two crops per year), and the field site at the Qingjiang station has a rotation of rapeseed-early rice-late rice (three crops per year). Agro-meteorological observations at these two sites recorded the dates of the squaring bolting, anthesis and maturity for rapeseed and the dates of emergence, transplanting, reviving, tilling, booting, tasseling, milky and maturity for early rice and late rice.

At the Yugan station, the observed bolting, anthesis and maturity dates for rapeseed correspond with the onset of the greenness increase, greenness maximum and greenness minimum in the first cycle of the EVI curve, and the reviving and maturity dates match the onset of the greenness increase and the previous time of the minimum greenness onset of the second cycle of the EVI curve. At the Qingjiang station, the rapeseed, early-rice and late-rice phenological stages are generally coincided with three seasonal cycles in the EVI curve. The reviving and maturity dates of early rice and late rice correspond to the onset of greenness and the previous time of the minimum greenness at the second cycle and third cycle, respectively. The highest greenness oc- curs at the tilling, booting and tasseling stages at both stations. In comparison to the double-cropping system, the triple-cropping area is more complicated because the crop calendar overlapped with the two continuous crop rotations. The emergence date of early rice is 20 days earlier than rapeseed maturity, and the emergence date of late rice is 20 days earlier than early rice maturity. The overlapped crop calendar results from rice seed germination in a nursery before field transplantation. The overlapping crop calendar is a typical and widely adopted cropping practice in the southern China, where transplanting is the common method of crop establishment for rice, which is often called 'rush-harvesting and rush-planting'.

At the Liaocheng station, the EVI values begin to increase gradually as winter wheat turned green with increasing temperature in spring. The EVI reach a plateau value after the wheat jointing stage and then reach its peak at the heading stage in mid-April, which take approximately 70 days from recovering to heading and 20 days from jointing to heading. After heading, the EVI decreas sharply to the minimum and reached maturity 45 days later. In the maize season, the EVI attain a plateau more rapidly than the winter wheat season, taking 50 days from emergence to heading, EVI reach the peak value at the maize jointing and then gradually decrease. In general, the MODIS EVI time series profile with 500 $\mathrm{m}$ resolution and an 8-day interval can capture the crop growth and crop rotation cycles and thus have the ability to detect multiple cropping intensity.

\subsection{Profiles of MODIS EVI time series data within different multiple cropping intensity}

In the EVI profiles derived from the MODIS time-series data, the EVI values show positive increments between
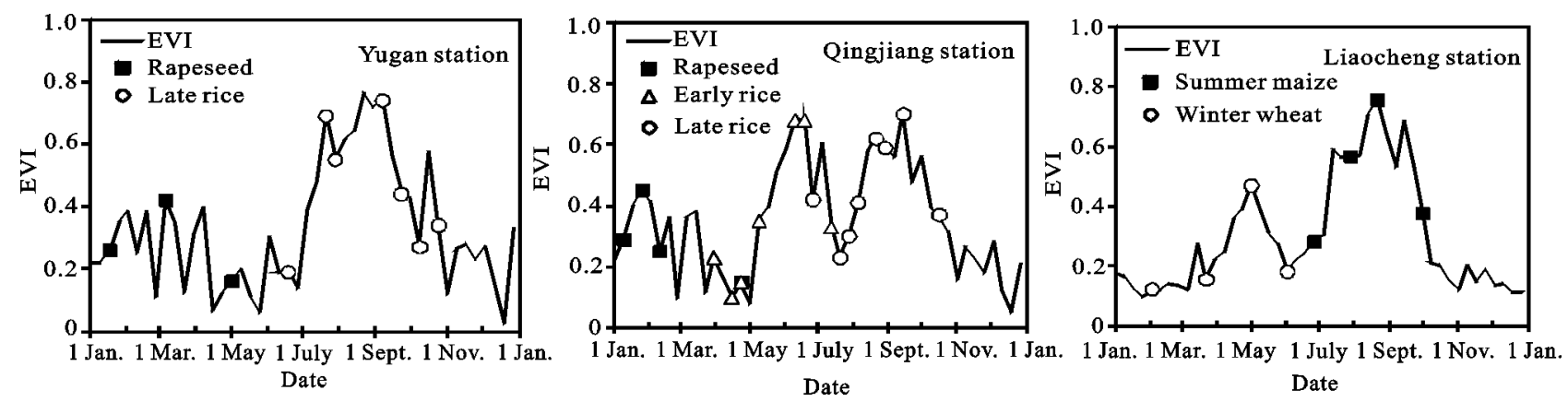

Fig. 5 Consistency between enhanced vegetation index (EVI) and crop calendar at three meteorological stations at most intensified cropping area in China (The symbols in the figures are key crop phenological phases from emergence (winter wheat reviving) to mature.) 
consecutive images when a crop starts to grow and then reaches a peak. When the crop approaches maturity, the EVI values decline gradually. Thus, the seasonal dynamics of the EVI at a single-cropping pixel has a unimodal growth curve, while at a double-cropping pixel, it exhibits as a bi-modal growth curve (Fig. 6). Consecutively, at a triple-cropping pixel, the EVI time series exhibits a tri-modal growth curve (Fig. 7). The profiles of the MODIS/EVI time series vary with crop types, the crop calendar and rotation management. Five parameters related to crop growth cycles can describe each of these crop growth curves, including the starting date, ending date, length of growing season, maximum EVI value and variant range of EVI.

Within each of six major agricultural regions, we sampled pixels that had the highest percentages of cropland according to the cropland distribution data, and an AMS should be close to the selected pixels. The seasonal profiles of the EVI data from those MODIS pixels were examined. We present six sites with a bi-modal profile of the EVI and four sites with a tri-modal profile of the EVI (Table 1).

The six sites with bi-modal EVI curves are from important double cropping regions, including Yugan, Suizhou, Lingshan, Jianyang, Luancheng and Shangluo (Fig. 6). The four sites with tri-modal EVI curves are from the triple-cropping dominated regions, including Qingjiang, Xuancheng, Yulin, and Jianyang (Fig. 7). The crop growth curves exhibit considerably different shapes among the six double-cropping regions. It is exceptional that three crop growth curves derived from Suizhou, Luancheng and Jianyang had equal EVI maximum values during two crop growing seasons and similar starting dates (mid-May) in the second crop cycle. However, both the starting and ending dates of the first crop cycle in the Luancheng Plain were slightly later than in the other regions, and the days of the second crop growing season in Suizhou station was lower than in Jianyang station. Crop growth curves of the double-cropping system in Yugan, Lingshan and Shangluo differed from the

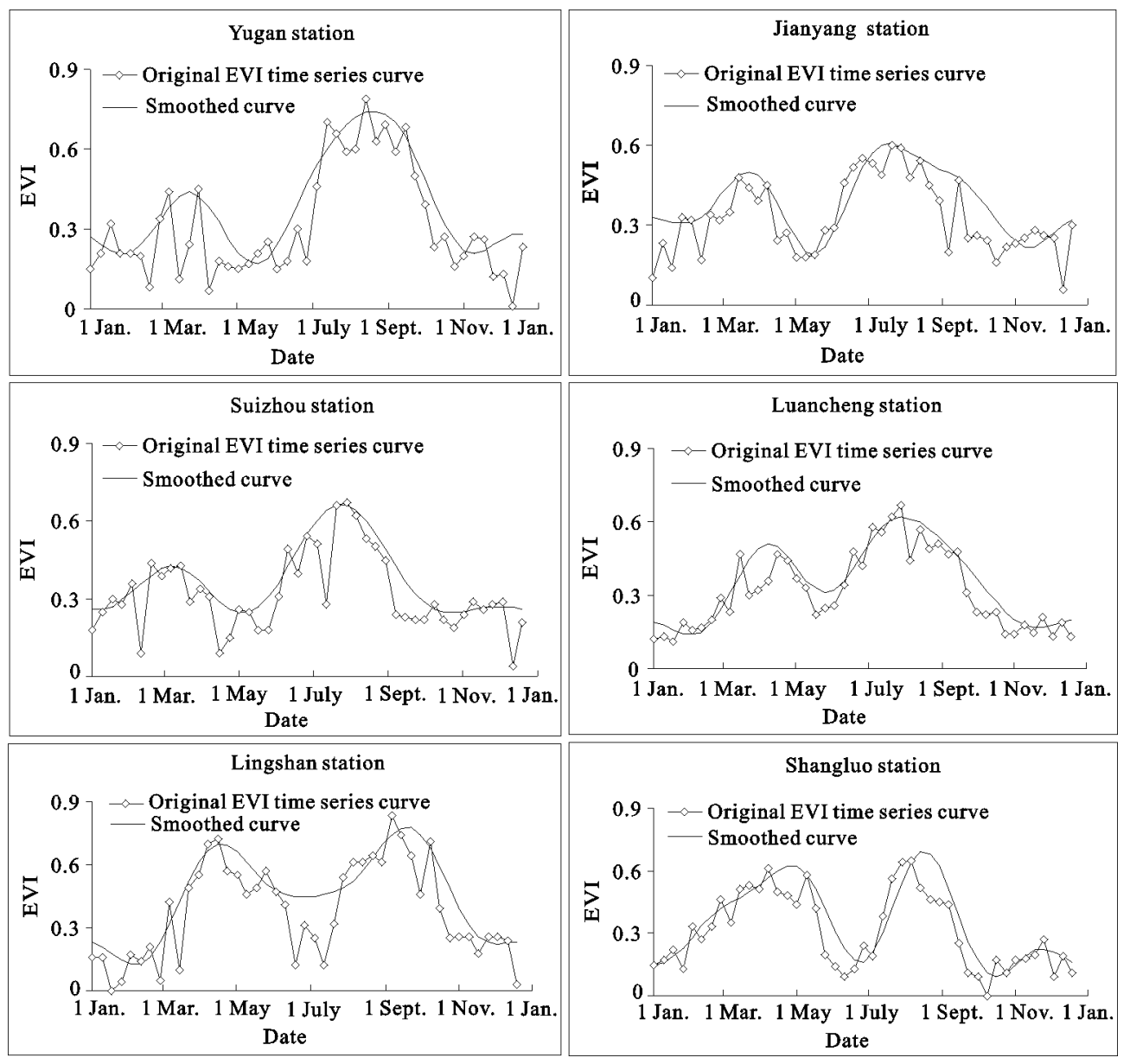

Fig. 6 Typical MODIS EVI time series curves and smoothed EVI curves in traditional double cropping regions of China 

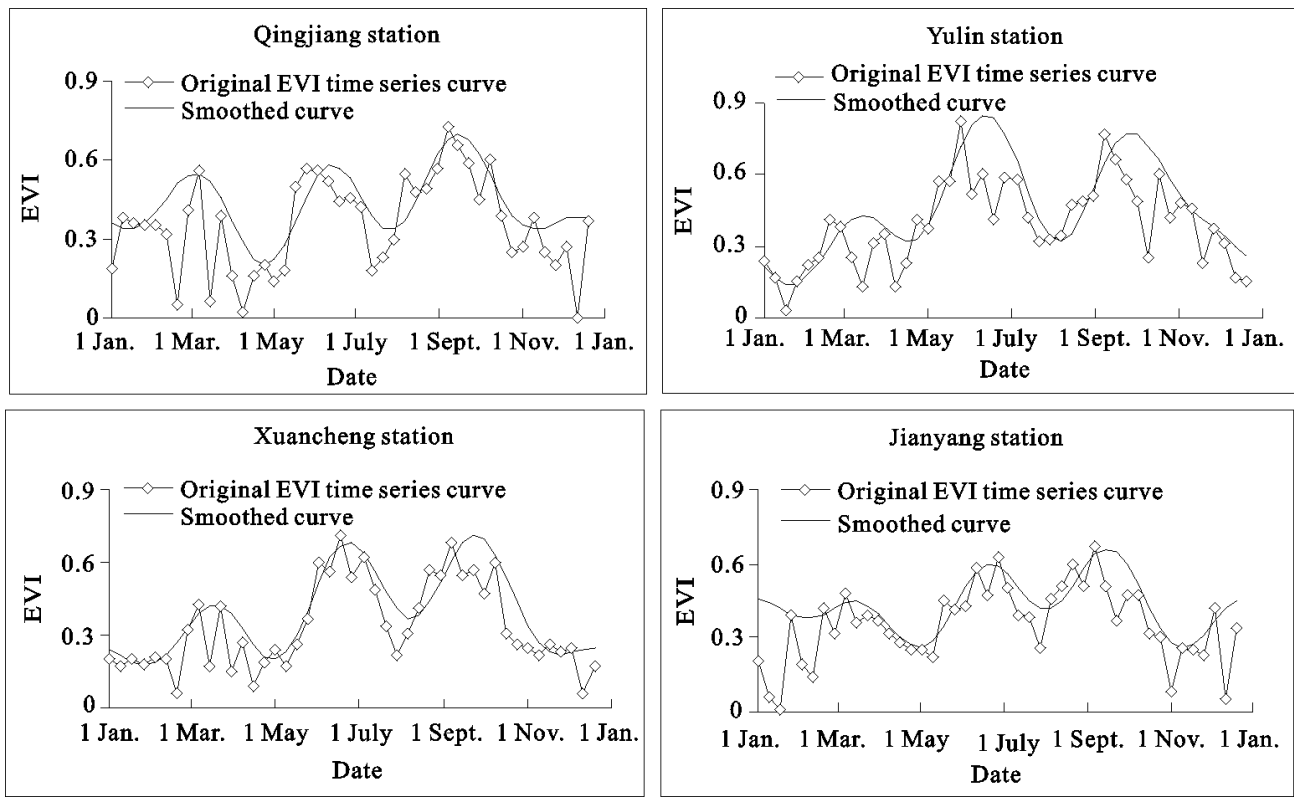

Fig. 7 Typical MODIS EVI time series curves and smoothed EVI curves in traditional triple cropping regions of China

Table 1 Double- and triple-cropping systems from selected sites in China

\begin{tabular}{ccccc}
\hline Station & Latitude & Longitude & Multiple cropping & Rotation \\
\hline Yugan & $28^{\circ} 42^{\prime} 00^{\prime \prime}$ & $116^{\circ} 40^{\prime} 59^{\prime \prime}$ & Double & Rapeseed-late rice \\
Suizhou & $30^{\circ} 02^{\prime} 17^{\prime \prime}$ & $113^{\circ} 10^{\prime} 08^{\prime \prime}$ & Double & Winter wheat-rice \\
Lingshan & $21^{\circ} 35^{\prime} 56^{\prime \prime}$ & $109^{\circ} 07^{\prime} 41^{\prime \prime}$ & Double & Early rice-late rice \\
Jianyang & $30^{\circ} 34^{\prime} 37^{\prime \prime}$ & $104^{\circ} 39^{\prime} 14^{\prime \prime}$ & Double & Winter wheat-cotton \\
Luancheng & $37^{\circ} 52^{\prime} 59^{\prime \prime}$ & $114^{\circ} 37^{\prime} 59^{\prime \prime}$ & Double & Winter wheat-summer maize \\
Shangluo & $34^{\circ} 31^{\prime} 01^{\prime \prime}$ & $109^{\circ} 11^{\prime} 20^{\prime \prime}$ & Double & Winter wheat-summer maize \\
Qingjiang & $28^{\circ} 03^{\prime} 58^{\prime \prime}$ & $115^{\circ} 32^{\prime} 60^{\prime \prime}$ & Triple & Rapeseed-early rice-late rice \\
Xuancheng & $30^{\circ} 57^{\prime} 50^{\prime \prime}$ & $118^{\circ} 21^{\prime} 04^{\prime \prime}$ & Triple & Rapeseed-early rice-late rice \\
Yulin & $22^{\circ} 35^{\prime} 48^{\prime \prime}$ & $110^{\circ} 06^{\prime} 18^{\prime \prime}$ & Triple & a-early rice-late rice \\
Jianyang & $29^{\circ} 44^{\prime} 53^{\prime \prime}$ & $104^{\circ} 43^{\prime} 12^{\prime \prime}$ & Triple & b \\
\hline
\end{tabular}

Notes: a, the first crop in the cropping growth cycle is not included in eight tracked crop types in the agro-meteorological data at the Yulin station; $b$, the curve is selected around the Jianyang station, but no corresponding crops match the three crop growth cycles in the EVI time series profile, and the reason might be that some other types of crops or vegetables apart from eight tracked crop types were planted around this area

counterparts in abovementioned three regions. The starting dates of the second growing season in Yugan, Lingshan and Shangluo occurred in late June, considerably later than in Suizhou, Luancheng and Jianyang. In Lingshan, the maximum EVI at both of the two crop seasons is higher than 0.7 , although the time of growing seasons of crops is basically the same. In Shangluo, the crop growth length of the first growth season is considerably longer than the second growth season. Conversely, in Yugan, the second growth season has a longer crop growth length than the first season, and the maximum EVI value is significantly higher than that in the first crop season. In the triple-cropping system, the crop growth curves of four selected stations are not as significantly different as those in the double-cropping areas because the crop rotation is highly limited by the temperature. The main difference is reflected in the maximum EVI of cropping growth cycles (Fig. 7).

\subsection{Spatial patterns of multiple cropping intensity in China}

According to the MODIS-derived multiple cropping distribution in 2002, the proportion of cropland cultivated with multiple crops reached $34 \%$ in China. Double-cropping accounted for approximately $94.6 \%$ and triple-cropping for $5.4 \%$. Figure 8 shows the distribution 
of multiple cropping across China, which was derived from the 2002 MODIS data. From the north to south in China, the cropping intensity patterns get diversified, at the north of the Great Wall only single-cropping, and single-, double- and triple-cropping all occurred in the South China. Croplands with multiple cropping practices, $77 \%$ of all pixels, were distributed in the HuangheHuaihe-Haihe plain (44\%) and the middle and lower reaches plains of the Changjiang (Yangtze) River (33\%), the two largest plains of China. In the Huanghe-HuaiheHaihe plain, the proportion of multiple cropping areas reached $58 \%$ of the total cropland and $19 \%$ in the mid- dle and lower reaches plains of the Changjiang River. Triple-cropping only accounted for $5.4 \%$ of the total multiple cropping area, of which $50 \%, 28 \%$ and $20 \%$ were distributed in the middle and lower reaches plains of the Changjiang River, the southwestern and the southern China, respectively. Among the 31 provinces (municipalities and autonomous regions included) of the mainland of China, 20 provinces had more than $10 \%$ of the cropland practicing multiple cropping (Fig. 9), and the multiple cropping areas were most extensively distributed in Anhui (83\%), Jiangsu (81\%) and Henan (76\%). More than half of the cropland in Hainan, Guang-

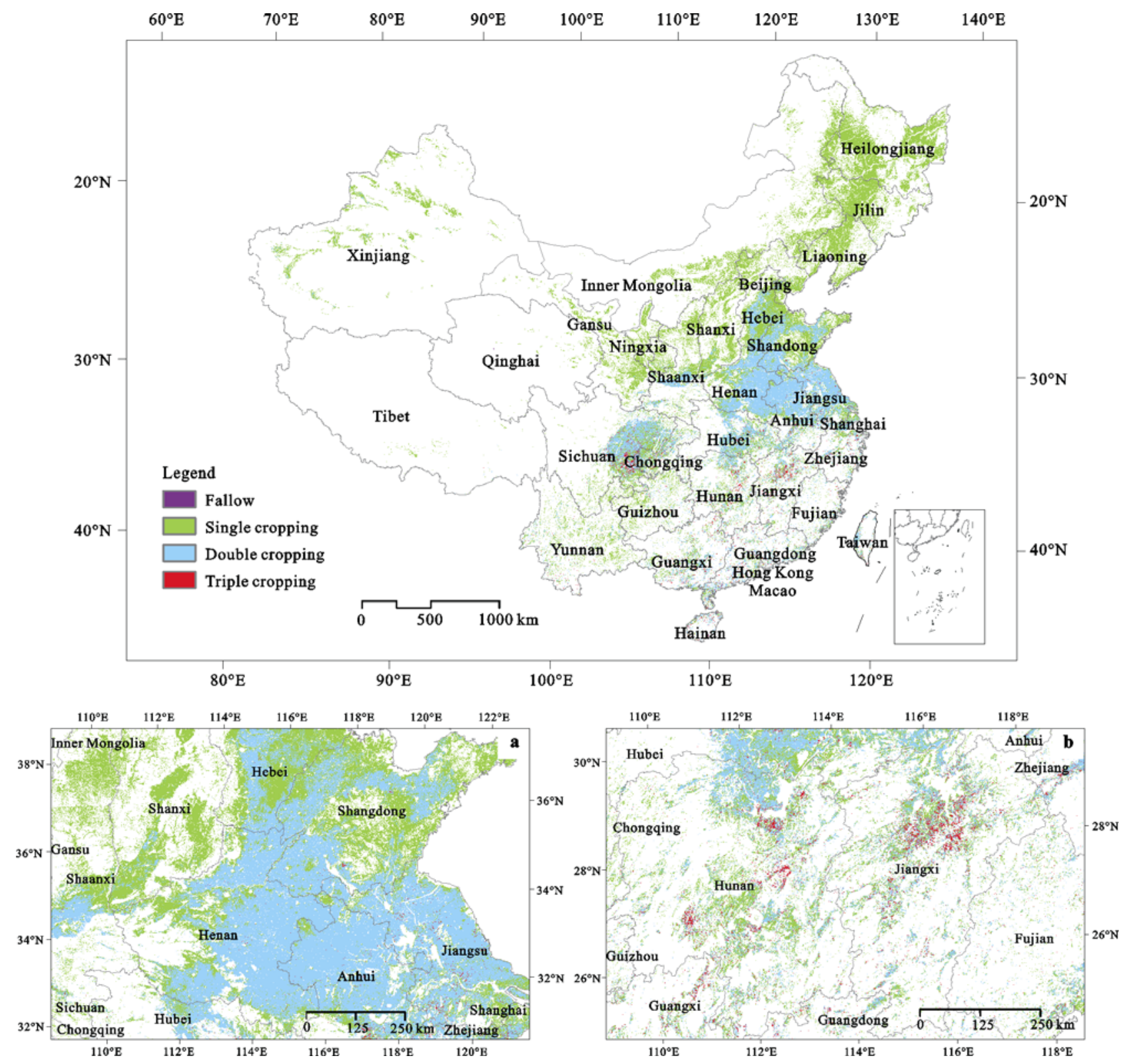

Fig. 8 Multiple cropping map of China in 2002 generated from MODIS time series data (Two enlarged maps show more details of Huanghe-Huaihe-Haihe plain (a) and Jiangxi Province (b).) 


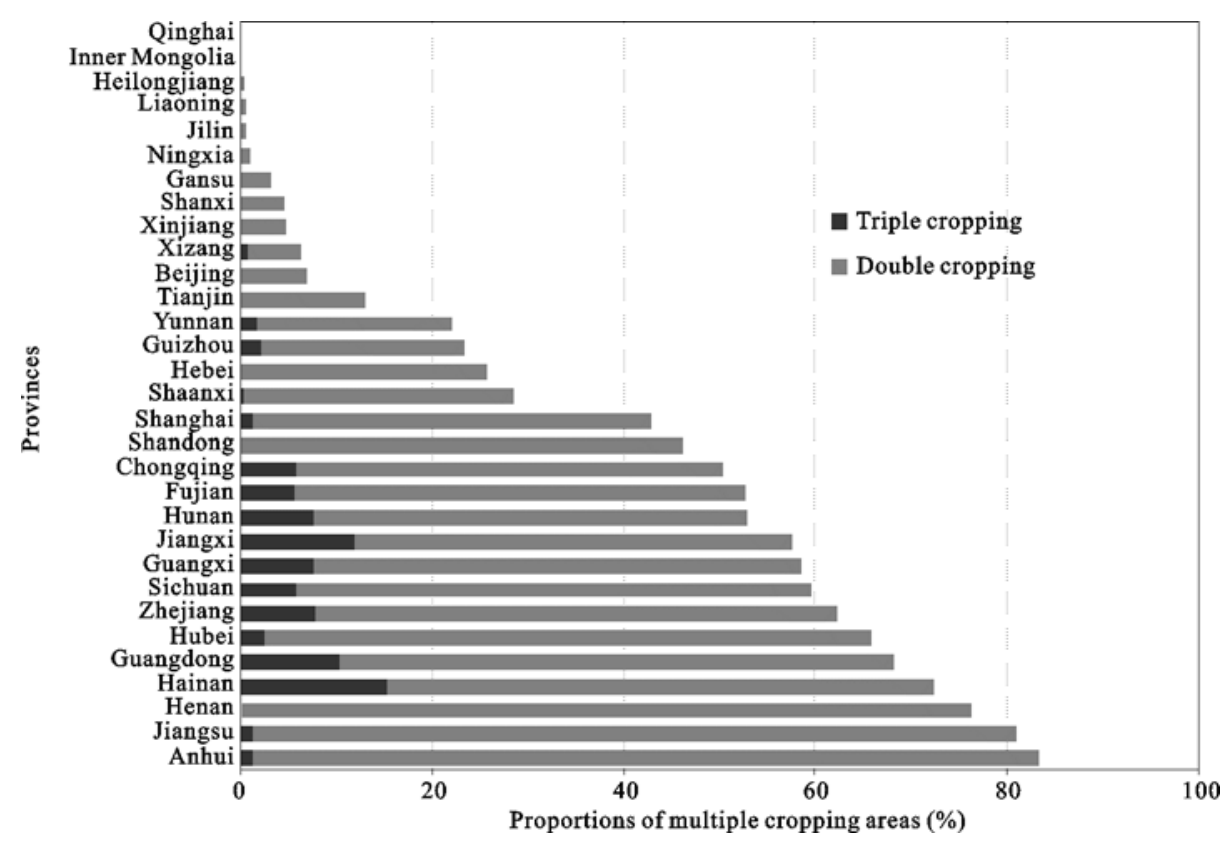

Fig. 9 Proportions of multiple cropping areas in different provinces of China

dong, Hubei, Zhejiang, Sichuan, Zhuang Auto momous Region of Guangxi, Jiangxi, Hunan and Fujian were also planted two or three times during the year, and the proportion of multiple cropping area within the total cropland area in Shandong and Shanghai are $46 \%$ and $43 \%$, respectively, the proportion of other provinces were lower than $30 \%$. The vastest distribution of triple cropping occurs in Hainan (15\%), Jiangxi (12\%) and Guangdong (10\%), while $21 \%$ of multiple cropping land are triple cropping in Jiangxi and Hainan also. In Guangdong, Hunan, Guangxi, Zhejiang, Chongqing, Fujian and Sichuan, the proportion of the triple cropping area within the total multiple cropping area are also high to $10 \%-15 \%$.

\section{Discussion}

The results of the multiple cropping map drawn from this study show that the total multiple cropping area occupies $34 \%$ of the total cropland area in China. However, $75 \%$ of the multiple cropping is distributed in the warm humid region of the eastern and central parts of the country, such as Jiangsu and Anhui. The double-cropping system is the most prevalent $(94.6 \%)$, and the triple-cropping system accounts for only $5.4 \%$ of the total multiple cropping areas. The developed spatial distribution of the multiple cropping intensity was highly coinciding with the in-situ crop calendar records derived map (Fig. 4). Within the 394 AMSs, 47\% (186 stations) were practiced with multiple cropping, and there were also 5.4\% (10 stations) triple cropping in the 186 multiple cropping stations. The spatial patterns of the multiple cropping areas developed by our methodology were similar to the distribution derived from agricultural census statistics when it was aggregated to a $0.5^{\circ}$ resolution (Qiu et al., 2003). The main discrepancy between the two maps was that the percentages of multiple cropping areas (especially triple-cropping) from agricultural census statistics were higher than the results of this study because the two maps were derived from different years and the uncertainty within different data sources. The agricultural census statistics-based method estimated that approximately $40 \%$ of the cropping area was multiple-cropped in 1990, while the estimation result of this study showed that the proportion of the multiplecropped area was $34 \%$ in 2002 . The triple-cropped area only took $5.4 \%$ within multiple-cropped lands in our results, significantly less than the agricultural census statistics which derived a $25 \%$ value.

The cropping system of China underwent great changes over the past 30 years, and according to our field survey in Jiangxi Province, large areas of triplecrop rotation (rice/rice/other crops) had been changed to single-cropping (single-rice) or double-cropping (rice/ rice or rice/other crops). A study in Hunan Province also reported that the proportion of double-rice area de- 
creased during 1994-1999, and the fallowed cropland area also increased (Xie and Li, 2001). Since grain output of China reached a high record in 1998, the total crop sown area, as well as the rice- and wheat-sown area, sharply declined until 2004. This may be one explanation of the lower proportion of the multiple cropped area and especially the triple cropped area. Moreover, there is also some inherent uncertainty due to the mixed pixel within satellite observed data at $500 \mathrm{~m}$ resolution. In China, no more than $40 \%$ of the MODIS-based multiple cropping pixels were located in the areas where cropland percentage was higher than $90 \%$ (pure pixel). In most densely populated areas, each family only has about 0.1 ha arable land, which indicates the number of family-owned fields varies from 1 to 250 within a pixel of $500 \mathrm{~m}$ by $500 \mathrm{~m}$. The crop rotations are determined by farmers and therefore vary between family-owned fields. The accuracy could be improved if satellite data with finer resolution were used for cropping intensity mapping in the future. The uncertainty of the data and method for agricultural census statistics method was described in the research of Qiu et al. (2003). The primarily source of uncertainty is the coarse resolution with $0.5^{\circ}$ grid produced by county level census statistics data, and another comes from the discrepancy between cropland map and sown area data. The satellite-based method with finer resolution used in this study is important for China as cropping intensity patterns are complicated not only due to diversified water and heat conditions, but also because of family-unit based cropland management practiced. Furthermore, it is a rapid method because the data used in census statistic based method require a longer preprocessed period before census data yearbook available for public use. Moreover, the two results come from completely different data sources can be verified each other.

\section{Conclusions}

This study used the 8-day time series MODIS (500 m) data and in situ observed crop growth calendar data to identify and map the distribution of multiple cropping intensity of China. The MODIS/EVI time series have ability to characterize crop rotation and cropping intensity, and the profiles of EVI track the differences of crop rotation and growth dynamics among different double-cropping or triple-cropping areas, therefore show a diverse phenological variation, which occur not only in the number of crop growth cycles but also in the phase, frequency and amplitude of the cycles. The in situ observations make us have a better cognition of cropping intensity patterns, and provide time difference information on start and end time of each crop types on national scale for establishing rules and thresholds in multiple cropping detection algorithms. The developed method provides an integrated approach for mapping and monitoring the multiple cropping intensity based on MODIS time-series data, which significantly improve the level of information and details on crop intensity distribution in China. This method is useful to perform rapid multiple cropping change assessment, and the resulted spatially explicit multiple cropping intensity map is helpful to evaluate the effects of intensified cropland management practices on biogeochemical cycles (including water, carbon and nitrogen) at regional and global scales.

This study describes the complex and varied situation of China's multiple cropping system using both in situ observed crop calendar data and satellite observed crop growth dynamics. Because of the diversity in crop types, crop planting and harvesting occurs consecutively throughout the year except in January and February. The crop calendar of winter wheat is closely related to temperature transition, but the planting time of early rice or late rice in the southern China is relatively irregular because economic conditions, flood risk and individual farmers' management all have profound impacts on cropping systems in sub-tropical or tropical areas. Because of a long growing season in the southern China, farmers have more options among crop types, crop rotation and cultivation methods, contributing to a more complex crop cultivation system. With the continually improved remote sensing techniques, the more detailed and explicit information of crop types and crop rotation should be derived from finer spatial and temporal resolutions images in the future.

\section{References}

Biradar C M, Xiao X M, 2011. Quantifying the area and spatial distribution of double- and triple-cropping croplands in India with multi-temporal MODIS imagery in 2005. International Journal of Remote Sensing, 32(2): 367-386. doi: 10.1080/ 01431160903464179

Cao M K, Prince S D, Shugart H H, 2002. Increasing terrestrial carbon uptake from the 1980 s to the 1990 s with changes in climate and atmospheric $\mathrm{CO}_{2}$. Global Biogeochemical Cycles, 
16(4): 1069. doi: 10.1029/2001GB001553

Defries R S, Field C B, Fung I et al., 1999. Combining satellite data and biogeochemical models to estimate global effects of human-induced land cover change on carbon emissions and primary productivity. Global Biogeochemical Cycles, 13(3): 803-815. doi: 10.1029/1999GB900037

Defries R S, Hansen M C, Townshend J R G, 2000. Global continuous fields of vegetation characteristics: A linear mixture model applied to multi-year $8 \mathrm{~km}$ AVHRR data. International Journal of Remote Sensing, 21(6-7): 1389-1414. doi: 10.1080/ 014311600210236

Dogliotti S, Rossing W A H, Ittersum M K, 2004. Systematic design and evaluation of crop rotations enhancing soil conservation, soil fertility and farm income: A case study for vegetable farms in South Uruguay. Agricultural Systems, 80(3): 277-302. doi: 10.1016/j. agsy.2003.08.001

Eickhout B, Bouwman A F, Van Z H, 2006. The role of nitrogen in world food production and environmental sustainability. Agriculture, Ecosystems \& Environment, 116(1-2): 4-14. doi: 10.1016/j.agee.2006.03.009

Foley J A, DeFries R, Asner G P et al., 2005. Global consequences of land use. Science, 309(5734): 570-574. doi: 10.1126/ science.111 1772

Friedl M A, McIver D K, Hodges J C F et al., 2002. Global land cover mapping from MODIS: Algorithms and early results. Remote Sensing of Environment, 83(1-2): 287-302. doi: 10.1016/S0034-4257(02)00078-0

Frolking S, Qiu J J, Boles S et al., 2002. Combining remote sensing and ground census data to develop new maps of the distribution of rice agriculture in China. Global Biogeochemical Cycles, 16(4): 1091. doi: 10.1029/2001GB001425

Frolking S, Xiao X M, Zhuang Y H et al., 1999. Agricultural land-use in China: A comparison of area estimates from ground-based census and satellite-borne remote sensing. Global Ecology and Biogeography, 8(5): 407-416. doi: 10.1046/j.1365-2699.199 9.00157.x

Huete A, Didan K, Miura T et al., 2002. Overview of the radiometric and biophysical performance of the MODIS vegetation indices. Remote Sensing of Environment, 83(1-2): 195-213. doi: 10.1016/S0034-4257(02)00096-2

Hurtt G C, Rosentrater L, Frolking S et al., 2001. Linking remote-sensing estimates of land cover and census statistics on land use to produce maps of land use of the conterminous United States. Global Biogeochemical Cycles, 15(3): 673-685. doi: 10.1029/2000GB 001299

Li C S, Zhuang Y H, Frolking S et al., 2003. Modeling soil organic carbon change in croplands of China. Ecological Applications, 13(2): 327-336. doi: 10.1890/1051-0761(2003) 013

Liu J Y, Liu M L, Deng X Z et al., 2002. The land use and land cover change database and its relative studies in China. Journal of Geographical Sciences, 12(3): 275-282. doi: 10.1007/ BF02837545

Liu J Y, Liu M L, Tian H Q et al., 2005. Spatial and temporal patterns of China's cropland during 1990-2000: An analysis based on Landsat TM data. Remote Sensing of Environment, 98(4): 442-456. doi: 10.1016/j.rse.2005.08.012

Liu J Y, Liu M L, Zhuang D F et al., 2003a. Study on spatial pattern of land-use change in China during 1995-2000. Science in China Series D: Earth Sciences, 46(4): 373-384. doi: 10.1360/ $03 y d 9033$

Liu J Y, Zhuang D F, Luo D et al., 2003b. Land-cover classification of China: Integrated analysis of AVHRR imagery and geophysical data. International Journal of Remote Sensing, 24(12): 2485-2500. doi: 10.1080/01431160110115582

Qiu J J, Tang H J, Frolking S et al., 2003. Mapping single-, double-, and triple-crop agriculture in China at $0.5^{\circ} \times 0.5^{\circ}$ by combining county-scale census data with a remote sensing-derived land cover map. Geocarto International, 18(2): 3-13. doi: 10.1080/10106040308542268

Ren W, Tian H Q, Xu X F et al., 2011. Spatial and temporal patterns of $\mathrm{CO}^{2}$ and $\mathrm{CH}_{4}$ fluxes in China's croplands in response to multifactor environmental changes. Tellus B, 63(2): 222-240. doi: 10.1111/j.1600-0889.2010.00522.x

Roerink G J, Menenti M, Verhoef W, 2000. Reconstructing cloudfree NDVI composites using Fourier analysis of time series. International Journal of Remote Sensing, 21(9): 1911-1917. doi: 10.1080/014311600209814

Sakamoto T, Van Nguyen N, Ohno H et al., 2006. Spatio-temporal distribution of rice phenology and cropping systems in the Mekong Delta with special reference to the seasonal water flow of the Mekong and Bassac rivers. Remote Sensing of Environment, 100(1): 1-16. doi: 10.1016/j.rse.2005.09.007

Sakamoto T, Yokozawa M, Toritani H et al., 2005. A crop phenology detection method using time-series MODIS data. Remote Sensing of Environment, 96(3-4): 366-374. doi: 10.1016/j.rse.2005.03.008

Stoate C, Boatman N D, Borralho R J et al., 2001. Ecological impacts of arable intensification in Europe. Journal of Environmental Management, 63(4): 337-365. doi: 10.1006/jema. 2001.0473

Stockholm, 2005. Global land project (GLP): Science plan and implementation strategy. IGBP (International GeosphereBiosphere Program) Report No.53/IHDP (International Human Dimensions Programme) Report No.19. Available at: www. igbp.net.

Tilman D, Balzer C, Hill J et al., 2011. Global food demand and the sustainable intensification of agriculture. Proceedings of the National Academy of Sciences of the United States of America, 108(50): 20260-20264. doi: 10.1073/pnas. 11164 37108

Verhoef W, Menenti M, Azzali S, 1996. A color composite of NOAA-AVHRR-NDVI based on time series analysis (19811992). International Journal of Remote Sensing, 17(2): 231235. doi: 10.1080/01431169608949001

Vitousek P M, Aber J D, Howarth R W et al., 1997. Human alteration of the global nitrogen cycle: Sources and consequences. Ecological Applications, 7(3): 737-750. doi: 10.1890/ 1051-0761(1997)007

Wu H B, Guo Z, Peng C, 2003. Land use induced changes of 
organic carbon storage in soils of China. Global Change Biology, 9(3): 305-315. doi: 10.1046/j.1365-2486.2003.00590.x

Xiao X M, Boles S, Frolking S et al., 2006. Mapping paddy rice agriculture in South and Southeast Asia using multi-temporal MODIS images. Remote Sensing of Environment, 100(1): 95-113. doi: 10.1016/j.rse.2005.10.004

Xiao X M, Boles S, Liu J Y et al., 2005a. Mapping paddy rice agriculture in southern China using multi-temporal MODIS images. Remote Sensing of Environment, 95(4): 480-492. doi: 10.1016/j.rse.2004.12.009

Xiao X M, Zhang Q Y, Saleska S et al., 2005b. Satellite-based modeling of gross primary production in a seasonally moist tropical evergreen forest. Remote Sensing of Environment, 94(1): 105-122. doi: 10.1016/j.rse.2004.08.015

Xiao X, Boles S, Frolking S et al., 2002a. Landscape-scale characterization of cropland in China using vegetation and Landsat TM images. International Journal of Remote Sensing, 23(18): 3579-3594. doi: 10.1080/01431160110106069

Xiao X, Boles S, Frolking S et al., 2002b. Observation of flooding and rice transplanting of paddy rice fields at the site to landscape scales in China using VEGETATION sensor data. International Journal of Remote Sensing, 23(15): 3009-3022. doi: 10.1080/01431160110107734

Xie Binggeng, Li Xiaoqing, 2001. Preliminary research of rural land use condition and countermeasure in Hunan province. Economic Geography, 21(6): 723-726. (in Chinese)

Yan H M, Cao M K, Liu J Y et al., 2007. Potential and sustainability for carbon sequestration with improved soil management in agricultural soils of China. Agriculture, Ecosystems and Environment, 121(4): 325-335. doi: 10.1016/j.agee.2006.

\subsection{8}

Yan H M, Fu Y L, Xiao X M et al., 2009. Modeling Gross Primary Productivity for winter wheat-maize double cropping system using MODIS time series and $\mathrm{CO}_{2}$ eddy flux tower data. Agriculture, Ecosystems and Environment, 129(4): 391400. doi: 10.1016/j.agee. 2008.10.017

Yan Huimin, Huang Heqing, Xiao Xiangming et al., 2008. Spatio-temporal distribution of multiple cropping systems in the Poyang Lake region. Acta Ecologica Sinica, 28(9): 4517-4523. (in Chinese)

Yan Huimin, Xiao Xiangming, Huang Heqing, 2010. Satellite observed spatio-temporal characteristics of multiple cropping and crop calendar in Huang-Huai-Hai plain. Acta Ecologica Sinica, 30(9): 2416-2423. (in Chinese)

Yang H, Li X, 2000. Cultivated land and food supply in China. Land Use Policy, 17(2): 73-88. doi: 10.1016/S0264-8377(00) 00008-9

Zhang X Y, Friedl M A, Schaaf C B et al., 2003. Monitoring vegetation phenology using MODIS. Remote Sensing of Environment, 84(3): 471-475. doi: 10.1016/S0034-4257(02)00135-9

Zhang X Y, Friedl M A, Schaaf C B, 2006. Global vegetation phenology from moderate resolution imaging spectroradiometer (MODIS): Evaluation of global patterns and comparison with in situ measurements. Journal of Geophysical Research, 111(G4): G04017. doi: 10.1029/2006JG000217

Zhang Y Q, Yu Q, Jiang J et al., 2008. Calibration of Terra/ MODIS gross primary production over an irrigated cropland on the North China Plain and an alpine meadow on the Tibetan Plateau. Global Change Biology, 14(4): 757-767. doi: 10.1111/ j.1365-248 6.2008.01538.x 